\title{
Does dexamethasone act in neuropeptides SP and CGRP in neurogenic inflammation of the skin? An experimental study ${ }^{1}$
}

\author{
Jose Octavio Gonçalves de Freitas ${ }^{\mathrm{I}}$, Paulo Rogério Quieregatto ${ }^{\mathrm{II}}$, Bernardo Hochman ${ }^{\mathrm{III}}$ in memoriam, Guilherme Abbud Franco \\ Lapin $^{\text {II }}$, Stella Maria Botequio Mella ${ }^{\text {IV }}$, Jessica Ruivo Maximinov, Gerson Chadi ${ }^{\text {VI }}$, Lydia Masako Ferreira ${ }^{\text {VII }}$
}

\author{
DOI: http://dx.doi.org/10.1590/S0102-865020150080000002
}

IFellow Master degree, Postgraduate Program in Translational Surgery, Division of Plastic Surgery, Universidade Federal de São Paulo (UNIFESP), Brazil. Conception and design of the study; acquisition, interpretation and analysis of data; manuscript preparation.

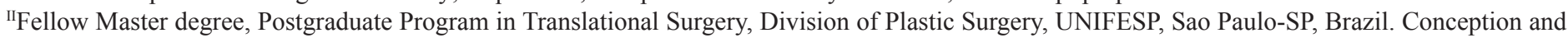
design of the study; acquisition, interpretation and analysis of data; manuscript writing.

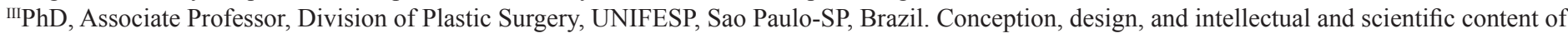
the study; acquisition, interpretation and analysis of data; manuscript writing; critical revision.

${ }^{\text {IV }}$ Graduate student, School of Medicine, UNIFESP. Grant from Institutional Program for Scientific Initiation (PIBIC) of the National Council of Scientific and Technological Development (CNPq) Ministry of Science, Technology and Inovation, Brazil. Conception and design of the study; acquisition, interpretation and analysis of data; manuscript preparation.

vPhD, Researcher, Neuroregeneration Center, Department of Neurology, School of Medicine, Universidade de São Paulo (USP), Brazil. Conception of the study; acquisition, interpretation and analysis of data; manuscript writing; critical revision.

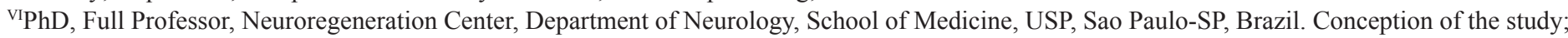
acquisition, interpretation and analysis of data; critical revision.

${ }^{V I I} \mathrm{PhD}$, Full Professor, Department of Surgery, UNIFESP, Sao Paulo-SP, Brazil. Conception, design, intellectual and scientific content of the study; interpretation and analysis of data; critical revision.

\section{ABSTRACT}

PURPOSE: To investigate the neuropeptides substance P (SP) and calcitonin gene-related peptide (CGRP) after subcutaneous injection of dexamethasone prior to skin incision in rats.

METHODS: Twenty seven Wistar-EPM-1 rats were randomly divided into three groups. The sham group (SG) of rats was injected with $0.9 \%$ saline. The second group (Dexa) was injected with $1.0 \mathrm{mg} / \mathrm{kg}$ dexamethasone, and the third group (Dexa + ) was injected with 10.0 $\mathrm{mg} / \mathrm{kg}$ dexamethasone. In all groups, the three subcutaneous injections were performed 30 minutes prior to the surgical skin incision and tissue collection. SP and CGRP (15 kDa pro-CGRP and $5 \mathrm{kDa}$ CGRP) were quantified by Western Blotting.

RESULTS: No statistically significant differences ( $p>0.05$ ) were found in pro-CGRP, CGRP and SP values in all three groups.

CONCLUSION: The anti-inflammatory effect of dexamethasone did not occur when the substance P and calcitonin gene-related peptide levels were altered during the neurogenic inflammation process of skin wound healing in rats.

Key words: Calcitonin Gene-Related Peptide. Substance P. Neuropeptides. Dexamethasone. Neurogenic Inflammation. Skin. Rats. 


\section{Introduction}

The sensory and autonomic nerve fibers of the skin have trophic and immuno modulatory properties that contribute to homeostasis and the wound healing process. Neurogenic inflammation is a tissue reaction associated with acute conditions in wound repair. It comprises a series of vascular and nonvascular inflammatory responses, triggered by the sympathetic activation of nociceptive nerve fibers A-Delta and $\mathrm{C}^{1-4}$ and the subsequent release of inflammatory neuropeptides, including substance P (SP) and calcitonin gene-related peptide (CGRP), among others ${ }^{5}$. In the skin, the neurogenic inflammation increases the blood flow, allowing the formation of edema and the exudation of plasma proteins. Primary lesions are described as erythematous papules or plaques with a pale center (wheal) and surrounding erythema (flare).

Substance $\mathrm{P}$ is one of the most potent vasodilators that releases nitric oxide from the endothelial cells. It activates the mast cells ${ }^{6}$, increases the production of histamine, leukotrienes and tumor necrosis factor-alpha (TNF-alpha); it also activates the endothelial cells ${ }^{7,8}$ so that they increase the expression of intercellular adhesion molecule-1 (ICAM-1), vascular cell adhesion molecule-1 (VCAM-1) and interleukin (IL); and it upregulates the production of IL-1 and IL- 8 in keratinocytes. SP is chemotactic in T cells, it increases the proliferation and function of $\mathrm{T}$ and $\mathrm{B}$ cells, induces the expression of IL- 1 and IL- 6 , increasing the production of immunoglobulins and the activity of natural killer-cells $(\mathrm{NK})^{9}$.

In contrast, the action of CGRP is slower, steadily progressive and of longer duration, inducing an intensive vasodilatation $^{10,11}$. As an a proinflammatory, CGRP is capable of activating mast cells, macrophages, fibroblasts, melanocytes, keratinocytes, dendritic cells and lymphocytes B and T, promoting the development of edema induced by IL-1 and IL-8, and is chemotactic to neutrophiles.

Neurogenic inflammation derives from and depends on the function and integrity of the sensory sympathetic nervous system. The amount and the secretory neuropeptidergic adjustment affect the intensity and the quality of the neurogenic inflammation phase of wound healing ${ }^{12}$. Therefore, the homeostatic status of skin may determine some possible changes of the healing process, when it is subjected to an incision or wound ${ }^{13}$.

In general, any tissue damage or painful stimulus can trigger neurogenic inflammation. There are several events that are capable of activating the neurosecretory activity of the skin nociceptors by means of physical, chemical or psychophysiological agents.
With regard to chemical stimuli, corticosteroids produce anti-inflammatory effects ${ }^{14,15}$, acting essentially on (1) the stabilization of the lysosomal membrane, (2) the inhibition of formation of kinins, which cause vasodilatation, increased capillary permeability and pain, and (3) the stabilization of the proliferation of fibroblasts and collagen production ${ }^{16,17}$. For tissue inflammation, dexamethasone inhibits erythema and edema, however, its mechanism of action is still uncleared. Yet, this effect is not extended to the inhibition of erythema and edema triggered by histamines, although SP also releases this compound ${ }^{18}$. Considering that dexamethasone is a potent anti-inflammatory agent with a well-known inhibitory action, the objective of the present study was to investigate whether a subdermal injection of dexamethasone prior to a skin incision would have effects on the secretion of neuropeptides SP and CGRP in the skin of rats.

\section{Methods}

The present study was approved by the Animal Care and Use Committee of the Universidade Federal de São Paulo (UNIFESP), approval number 1926/10. The use of laboratory animals followed the principles of the Brazilian College on Animal Experimentation (COBEA), the Federal Law number $11.794(08 / 10 / 2008)$ and the decree 6.689 (15/07/2009). The study is classified as United States Department of Agriculture (USDA) Category $\mathrm{C}$ for laboratory animal usage.

The procedures were performed at the Experimental Surgery Laboratory of the Surgery Department of the institution.

The sample consisted of 27 adult male Wistar EPM-1 rats (Rattus norvegicus: albinus, Rodentia, Mammalia), 260-300g body weight, eight weeks of age. The animals were housed in individual propylene cages 15 days before the procedure, received food and ad libitum water. The temperature was maintained at $22^{\circ} \mathrm{C}$ with a light dark cycle of $12 / 12 \mathrm{~h}$.

The animals were randomly divided into three groups with nine rats each (software Bioestat ${ }^{\circledR}$ 3.0). Sham Group (Sham) of rats was injected with $0.9 \%$ saline. Dexa group was injected with $1.0 \mathrm{mg} / \mathrm{kg}$ dexamethasone and Dexa+ group received 10.0 $\mathrm{mg} / \mathrm{kg}$ of dexamethasone. In all groups, the three subcutaneous injections were performed 30 minutes prior to the surgical skin incision and tissue collection to quantify the neuropeptides.

For the experimental procedures, the animals were anesthetized by intramuscular injection in the right hind leg using tiletamine hydrochloride in association with zolazepam hydrochloride, $10 \mathrm{mg} / \mathrm{kg}$ (Zoletil ${ }^{\mathrm{TM}} 50 \mathrm{mg}$ ), after pre-anaesthetic medication with intramuscular acepromazine $0.025 \mathrm{mg} / \mathrm{kg}\left(\right.$ Acepran $\left.^{\circledR} 0.2 \%\right)$. 
Subsequently, each animal was placed in the ventral decubitus position, immobilized on a surgery board for digital hair removal of an area measuring $12 \mathrm{~cm}$ long x $6 \mathrm{~cm}$ large in the cranial-caudal direction. The adopted cranial limit was at the superior margin of scapula. A straight line was demarcated with 2 $\mathrm{cm}$ in the cranial-caudal direction, on the dorsal midline, starting from the transverse line between the scapular inferior lines.

All samples from the three groups were submitted to subcutaneous injection with $1.0 \mathrm{ml}$ solution. In Sham, the rats were treated with $0.9 \%$ saline solution; Dexa group was treated with solution containing $1 \mathrm{mg} / \mathrm{kg}$ dexamethasone disodium phosphate, and Dexa + group received $10 \mathrm{mg} / \mathrm{kg}$ of dexamethasone sodium phosphate. The injection of each solution was performed subdermally under the demarcation line, 30 minutes before the incision, using a $1.0 \mathrm{ml}$ syringe with $25 \mathrm{x} 0.8 \mathrm{~mm}$ needle. The solution was injected by a puncture in the caudal point of the straight line segment, using the bezel of a hypodermic needle introduced subdermally into the cranial extremity. The solution of $0.1 \mathrm{ml}$ was injected every $2 \mathrm{~mm}$ in a cranial-caudal retroinjection movement. After 30 minutes, the skin was incised using a surgical blade (number 15). The skin of interest was extended until the superficial fascia. All animals were operated by the same researcher blinded to all groups.

Following incision, all animals were submitted to a painless assisted death with an intracardiac injection of $1.0 \mathrm{~mL}$ potassium chloride at $19.1 \%$, followed by a cervical-cranial dislocation. An electrical dermatome $\left(\right.$ Padget $\left.^{\circledR}\right)$ was used to remove a skin sample from the dorsal mid sagittal line of $2 \mathrm{~cm}^{2}$ containing the incision. Thickness was adjusted to $0.5 \mathrm{~mm}$.

These skin fragments provided the samples for the quantification of SP, pro-CGRP (15 KDa) and CGRP (5-KDa active form) marked with an $8 \mathrm{~mm}$ in diameter punch, at the central midpoint of the incision. The samples were stored in Eppendorf tubes at temperatures ranging from -2.0 to $-6.0^{\circ} \mathrm{C}$ and sent to the laboratory for processing and Western Blotting analysis.

\section{Western blotting}

Fragments collected from each animal werehomogenized in buffered solution for total protein extraction. The amount of protein was determined according to the Bradford method ${ }^{19}$. The buffered solution was prepared with Trizma ${ }^{\circledR}(25 \mathrm{mmol} / \mathrm{L})$, glicina $(0,2 \mathrm{~mol} / \mathrm{L})$ e $\operatorname{SDS}(0.1 \%)$, the proteins were separated by applying 100 volts for one hour and 30 minutes. The samples (60 $\mu \mathrm{g}$ protein/well) were applied to $12 \%$ polyacrylamide gel wells for separation (sodium dodecyl sulfate-polyacrylamide gel electrophoresis, SDS-PAGE).

The proteins were then transferred to polyvinylidene fluoride (PVDF) membrane $\left(\right.$ Bio-Rad $\left.^{\circledR}\right)$ for 1 hour at $100 \mathrm{~V}$ and blocked in solution composed by $10 \%$ milk in tris-buffered saline with Tween-20 (TBS-T) at $0.05 \%$ for 15 minutes at room temperature. After blocking, the membranes were incubated with primary antibodies: anti-substance $\mathrm{P}$ produced in goats $(1 / 100$, Santa $\mathrm{Cruz}^{\circledR}$ ) and anti-CGRP polyclonal antibody produced in rabbits $(1 / 300$, Sigma) both diluted in milk (3\%) in TBS-T for 24 hours at $4^{\circ} \mathrm{C}$ under constant stirring. After incubation, the membranes were washed twice for 10 minutes in TBS-T and incubated with the secondary antibodies, anti-goat and antirabbit (1/2.000, GE and 1/10.000, GE, respectively) conjugated to a peroxidase [horseradish peroxidase (HRP)-conjugated], diluted in milk (3\%) in TBS-T and incubated for 1 hour at room temperature. Subsequently, the membranes were washed twice in TBS-T and once in TBS for 10 minutes each and incubated with chemiluminescent reagent (Western Lightning Chemiluminescence Reagent Plus, ECL kit, Perkinelmer ${ }^{\circledR}$, EUA) for 1 minute. The membranes were exposed to a chemiluminescent-sensitive film (Hyperfilm ECL, Amersham Biosciences $^{\circledR}$ ) and revealed according to the manufacturer's instructions. The membranes were then incubated with primary antibody against beta-actin diluted at 1:30.000 (Sigma) in TBS-T with $1 \%$ bovine serum albumin (BSA) for one hour at room temperature, then washed twice for 10 minutes with TBS-T and incubated for 45 minutes at room temperature with the secondary antibody (anti-rabbit, HRP-conjugated, Amersham) diluted at $1: 10.000$ in TBS-T with $1 \%$ BSA. After these incubations, the membranes were washed as previously described, followed by reaction and film developing.

The films were digitized (HP Scanjet G4000 series) and the protein levels of SP, Pro-CGRP and CGRP were quantified by optical densitometry using ImageJ software, version 1.43u (National Institutes of Health). The band densities were normalized with $\beta$-tubulin III.

\section{Statistical analysis}

In the Western Blotting analysis of the experiments, the one-way analysis of variance (ANOVA) was applied, using Tukey's multiple comparison post test to identify statistical significances between groups. All analyses were performed using Prism 5.0 (Graph Pad). Data were presented as mean \pm SEM and significance level was set at $\mathrm{p}<0.05$. 


\section{Results}

The results showed that there neuropeptides release in three groups, but there were no statistically significant differences $(p>0.05)$ in the values found for SP $(p=0.32)$, pro-CGRP $(p=0.56)$ and CGRP ( $\mathrm{p}=0.53$ ) among the groups (Figure 1).
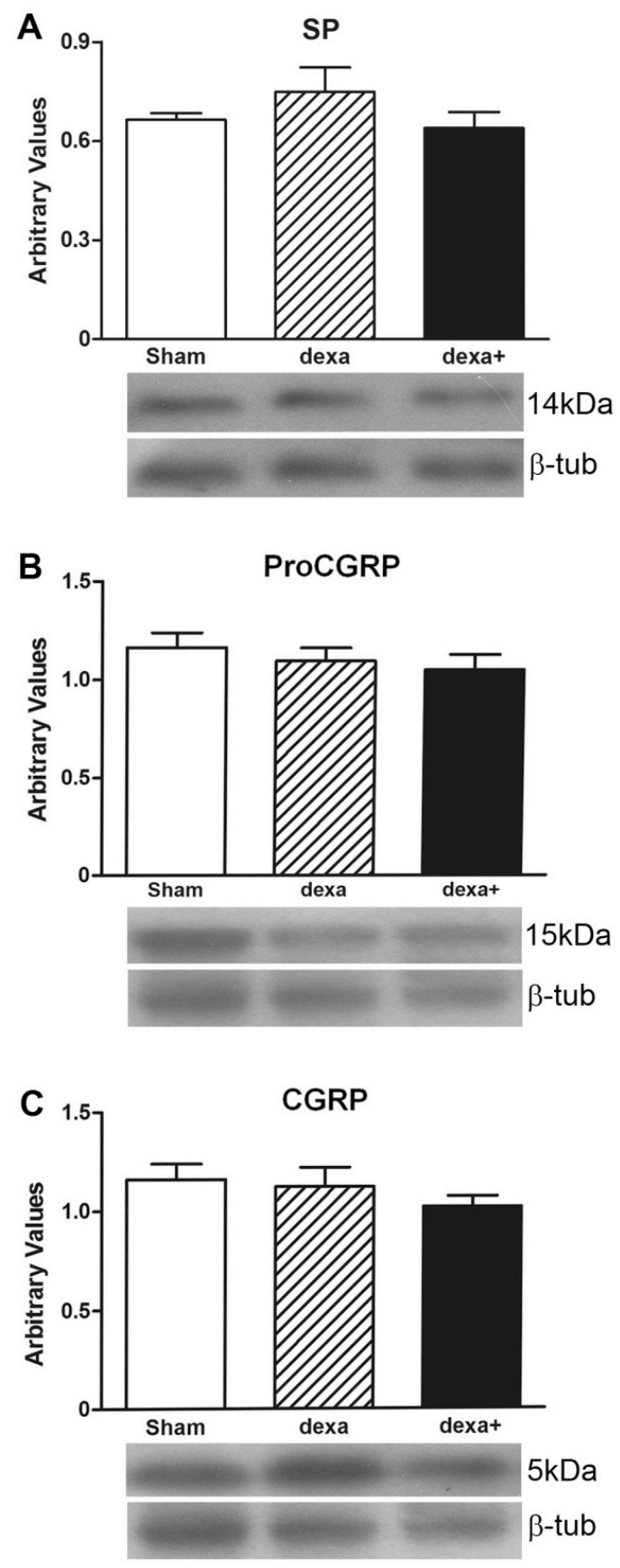

FIGURE 1 - Western blotting analysis. The relative optical density of (A) Substance P (SP), (B) pro-CGRP and (C) CGRP by means of Western Blotting analysis in the incised rat skin of control (Sham), Dexa (1 mg/ $\mathrm{kg})$ and Dexa $+(10 \mathrm{mg} / \mathrm{kg})$ groups $(\mathrm{n}=9)$. $\beta$-Tubulin III $(\beta$-tub) was used as sample loading control. The representative bands of the SP $(14 \mathrm{kDa})$ of animals as well as $\beta$-tub $(55 \mathrm{kDa})$ are illustrated.

\section{Discussion}

The healing of a skin wound is a complex process involving inflammation, reepithelization, angiogenesis, the formation of granulation tissue and interstitial matrix deposition, which are performed by different types of cells, such as keratinocytes, fibroblasts, inflammatory and endothelial cells ${ }^{20}$. Initially, however, mechanical stress on the margins of the wound stimulates mechanosensitive nociceptors on sensory fibers in the skin. Stimulated fibers release neuropeptides, including SP and CGRP ${ }^{21}$. The principal trigger of neurogenic inflammation is the activation of immunoinflammatory and pro-inflammatory substances resulting in an increase in the blood flow and consequent edema caused by the exudation of plasma from the post-capillary venula ${ }^{22}$.

Both SP and CGRP are present in cutaneous nerve fibers of type $\mathrm{C}$ and $\mathrm{A}-\delta$, which are the main fibers responsible for the healing process. These neuropeptides are also present in sweat and sebaceous glands, in mechanoreceptors and in perivascular innervations ${ }^{9,23}$. Some neuropeptides co-exist in the same nerve fibers and are co-released upon nerve stimulation ${ }^{24}$.

Neuropeptides released from cutaneous nerves act on target cells which express specific receptors that are coupled to an intracellular signal transduction pathway or ion channels ${ }^{13}$, which, when released, may result in erythema, edema, hyperthermia, and pruritus that activate local immune system cells that release prostaglandins, histamine, cytokines, proteases and immunoglobulins.

This mechanism has cast doubts that has guided our study; although the neuropeptides are released via neurogenic inflammation, the question was whether the local injection of corticoids (anti-inflammatory drugs), such as dexamethasone, could inhibit the response of neurogenic inflammation or affect the release of SP and CGRP induced by skin nociceptive stimuli in rats.

Corticosteroids act on inflammation ${ }^{25}$ to reduce the circulation of inflammatory cells, mainly during the initial stage ${ }^{26}$, in surgical wounds. However, corticosteroids inhibit not only the initial stage of erythema, hyperthermia, pain and edema, but also the later stages of wound healing and wound repair and proliferative responses observed in chronic inflammation. In this context, subcutaneous dexametasona treatment for eight consecutive days strongly interfered with both the synthesis and degradation of type I collagen and, more drastically, type III collagen, the molecule that is known to play a major role in the initiation of wound healing ${ }^{14}$. 
There are some substances that can influence or modulate the neurogenic inflammation phase. Peptidases are among these substances, which are SP and CGRP degrading enzymes such as neutral endopeptidase (NEP) and tryptase; and substances that act by depletion or inhibition of secretion of free nerve endings, such as capsaicin, topic morphine and local anesthetics ${ }^{27}$. However, this modulation is not yet completely understood, therefore, further studies on the substances that interfere with the sensitivity of the skin and the release of neuropeptides are necessary.

For the influence of corticosteroids on neurogenic inflammation, this study has showed that soon after cutaneous nociceptive stimuli (incision), there was no quantitative difference of neuropeptides CGRP and SP in subcutaneous injections of dexamethasone either in therapeutic dose $(1 \mathrm{mg} / \mathrm{kg})$ or in an acute overdosage $(10 \mathrm{mg} / \mathrm{kg})$. In fact, dexamethasone does not act locally on neurosecretory signaling of these neuropeptides. The release of neuropeptides occurs primarily as a direct consequence of the nociceptive stimulus through an axonal reflection of sensory nerve fibers type A- $\delta$ and C. Dexamethasone, independent of its inhibitory influence on the immuno-endocrine component of inflammation, fails to reduce the release of these inflammatory substances through the nerve endings. For the topically applied corticosteroids, a previous experimental study has reported that both dexamethasone and betamethasone are not able to inhibit the secretion of SP in atopic dermatitis, even after additional seven days. This finding revealed that these steroids have no influence on the neurosecretory inflammation pathways, which corroborates the results of the present study ${ }^{28}$.

The literature describes neuropeptide release from nerve endings as an event derived from an axonal reflex ${ }^{13}$. In the present study, the nociceptive stimuli (incision) occurred after 30 minutes of dexamethasone injection. This period of time was probably not enough for the anti-inflammatory to act on the nerve endings. However, 30 minutes seemed an appropriate time because the peak of this substance in the tissue occurred 2.5 to 20 minutes following the injection of the $\mathrm{drug}^{29}$.

In clinical practice, the use of corticosteroids via intralesional with the purpose of minimize inflammation is routine, but there is no experimental study to validate this approach. The CGRP and SP research has its importance to quantify the degree of inflammation at the beginning of the healing process.

The study of neuropeptides in the skin of rats, as the measuring method of the inflammatory process early in the healing process was used by several authors. Hochman et al. ${ }^{30}$ revised the influence of laser beams in rat skin by measuring the secretion of the neuropeptides CGRP and SP. Raymundo et $a l .{ }^{31}$ used the same methodology to study the effects of carbon dioxide in the skin of rats. The authors demonstrated to be a useful tool to infer current and inflammation involved early in the healing process.

Subdermal dexamethasone did not act on the secretion of cutaneous neuropeptides analyzed in this study and was apparently innocuous in the biochemical pathways of neurogenic inflammation. Thus further research is needed to investigate whether the systemic use of dexamethasone could have a quantitative and/or qualitative impact on the levels of CGRP and SP during neurogenic inflammation.

Studies on skin inflammation involving neuropeptides, are rare and find themselves at the beginning of its activities, which could explain the lack of current studies in the literature on the subject.

\section{Conclusion}

The anti-inflammatory effect of dexamethasone did not occur when the substance $\mathrm{P}$ and calcitonin gene-related peptide levels were altered during the neurogenic inflammation process of skin wound healing in rats

\section{References}

1. Richards AM, Floyd DC, Terenghi G, McGrouther DA. Cellular changes in denervated tissue during wound healing in a rat model. Br J Dermatol. 1999 Jun;140(6):1093-9. PMID: 10354076.

2. Schmelz M, Petersen LJ. Neurogenic inflammation in human and rodent skin. Neurogenic inflammation in human and rodent skin. News Physiol Sci. 2001 Feb;16:33-7. PMID: 11390944.

3. Souza BR, Cardoso JF, Amadeu TP, Desmoulière A, Costa AM. Sympathetic denervation accelerates wound contraction but delays reepithelialization in rats. Wound Repair Regen. 2005 SepOct;13(5):498-505. PMID: 16176458.

4. Hochman B, Locali RF, Matsuoka PK, Ferreira LM. Intralesional triamcinolone acetonide for keloid treatment: a systematic review. Aesthetic Plast Surg. 2008 Jul;32(4):705-9. PMID: 18418647.

5. Geppetti P, Nassini R, Materazzi S, Benemei S. The concept of neurogenic inflammation. BJU Int. 2008 Mar;101 Suppl 3:2-6. PMID: 18307678.

6. Ansel JC, Brown JR, Payan DG, Brown MA. Substance P selectively activates TNF-alpha gene expression in murine mast cells. J Immunol. 1993 May 15;150(10):4478-85. PMID: 7683320.

7. Quinlan KL, Song IS, Naik SM, Letran EL, Olerud JE, Bunnett NW, Armstrong CA, Caughman SW, Ansel JC. VCAM-1 expression on human dermal microvascular endothelial cells is directly and specifically up-regulated by substance P. J Immunol. 1999 Feb 1;162(3):1656-61. PMID: 9973426.

8. Quinlan KL, Naik SM, Cannon G, Armstrong CA, Bunnett NW, Ansel JC, Caughman SW. Substance P activates coincident NF-AT- and NFkappa B-dependent adhesion molecule gene expression in microvascular endothelial cells through intracellular calcium mobilization. J Immunol. 1999 Nov 15;163(10):5656-65. PMID: 10553096. 
9. Lotti T, Hautmann G, Panconesi E. Neuropeptides in skin. J Am Acad Dermatol. 1995 Sep;33(3):482-96. PMID: 7657872.

10. Wallengren J. Vasoactive peptides in the skin. J Investig Dermatol Symp Proc. 1997 Aug;2(1):49-55. PMID: 9487016.

11. Godoy GR, Liebano RE, Corrêa JB, Hochman B, Ferreira LM. Capsaicin on the viability of random-pattern skin flaps in rats. Acta Cir Bras. 2010 Oct;25(5):440-3. PMID: 20877955.

12. Ferreira LM, Gragnani A, Furtado F, Hochman B. Control of the skin scarring response. An Acad Bras Cienc. 2009 Sep;81(3):623-9. PMID: 19722029.

13. Roosterman D, Goerge T, Schneider SW, Bunnett NW, Steinhoff M. Neuronal control of skin function: the skin as a neuroimmunoendocrine organ. Physiol Rev. 2006 Oct;86(4):130979. PMID: 17015491.

14. Oishi Y, Fu ZW, Ohnuki Y, Kato H, Noguchi T. Molecular basis of the alteration in skin collagen metabolism in response to in vivo dexamethasone treatment: effects on the synthesis of collagen type I and III, collagenase, and tissue inhibitors of metalloproteinases. $\mathrm{Br}$ J Dermatol. 2002 Nov;147(5):859-68. PMID: 12410694.

15. Hochman B, Nahas FX, Sobral CS, Arias V, Locali RF, Juliano Y, Ferreira LM. Nerve fibres: a possible role in keloid pathogenesis. Br J Dermatol. 2008 Mar;158(3):651-2. PMID: 18205867.

16. Klemm P, Harris HJ, Perretti M. Effect of rolipram in a murine model of acute inflammation: comparison with the corticoid dexamethasone. Eur J Pharmacol. 1995 Jul 25;281(1):69-74. PMID: 8566119

17. Tennius FP, Biondo-Simoes MLP, Iosbii SO. Effects of chronic use of dexamethasone on cutaneous wound healing in rats. An Bras Dermatol. 2007;82(2):141-9. doi: 10.1590/S036505962007000200005

18. Okabe T, Hide M, Koro O, Nimi N, Yamamoto S. The release of leukotriene B4 from human skin in response to substance P: evidence for the functional heterogeneity of human skin mast cells among individuals. Clin Exp Immunol. 2001 Apr;124(1):150-6. PMID: 11359454.

19. Bradford MM. A rapid and sensitive method for the quantitation of microgram quantities of protein utilizing the principle of protein-dye binding. Anal Biochem. 1976 May 7;72:248-54. PMID: 942051.

20. Martin P. Wound healing--aiming for perfect skin regeneration. Science. 1997 Apr 4;276(5309):75-81. PMID: 9082989.

21. Akaishi S, Ogawa R, Hyakusoku H. Keloid and hypertrophic scar: neurogenic inflammation hypotheses. Med Hypotheses. 2008;71(1):32-8. PMID: 18406540.

22. Kalil-Gaspari P. Neuropeptides in the skin. An Bras Dermatol. 2003 Jul-Ago;78(4):483-98. doi: 10.1590/S0365-05962003000400010.

23. Johansson $\mathrm{O}$, Fantini $\mathrm{F}, \mathrm{Hu} \mathrm{H}$. Neuronal structural proteins, transmitters, transmitter enzymes and neuropeptides in human Meissner's corpuscles: a reappraisal using immunohistochemistry. Arch Dermatol Res. 1999 Jul-Aug;291(7-8):419-24. PMID: 10482012 .

24. Wallengren J, Ekman R, Sundler F. Occurrence and distribution of neuropeptides in the human skin. An immunocytochemical and immunochemical study on normal skin and blister fluid from inflamed skin. Acta Derm Venereol. 1987;67(3):185-92. PMID: 2442929.

25. Leibovich SJ, Ross R. The role of the macrophage in wound repair. A study with hydrocortisone and antimacrophage serum. Am J Pathol. 1975 Jan;78(1):71-100.

26. Nguyen H, Lim J, Dresner ML, Nixon B. Effect of local corticosteroids on early inflammatory function in surgical wound of rats. J Foot Ankle Surg. 1998 Jul-Aug;37(4):313-8. PMID: 9710784.
27. Rook JM, McCarson KE. Delay of cutaneous wound closure by morphine via local blockade of peripheral tachykinin release. Biochem Pharmacol. 2007 Sep 1;74(5):752-7. PMID: 17632084

28. Fujii Y, Sengoku T, Takakura S. Repeated topical application of glucocorticoids augments irritant chemical-triggered scratching in mice. Arch Dermatol Res. 2010 Nov;302(9):645-52. PMID: 20549223.

29. Moussy Y, Dungel P, Hersh L. Diffusion of $[3 \mathrm{H}]$ dexamethasone in rat subcutaneous slices after injection measured by digital autoradiography. Biotechnol Prog. 2006 Nov-Dec;22(6):1715-9. PMID: 17137323.

30. Hochman B, Pinfildi CE, Nishioka MA, Furtado F, Bonatti S, Monteiro PK, Antunes AS, Quieregatto PR, Liebano RE, Chadi G, Ferreira LM. Low-level laser therapy and light-emitting diode effects in the secretion of neuropeptides SP and CGRP in rat skin. Lasers Med Sci. 2014 May;29(3):1203-8. PMID: 24337394.

31. Raymundo EC, Hochman B, Nishioka MA, Gonçalves de Freitas JO, Maximino JR, Chadi G, Ferreira LM. Effects of subcutaneous carbon dioxide on calcitonin gene related peptide and substance $\mathrm{P}$ secretion in rat skin. Acta Cir Bras. 2014 Apr;29(4):224-30. PMID: 24760022 .

\section{Acknowledgements}

To the team of Pathological Scar Plastic Surgery Unit (UNIFESP) and, especially, Arainy Antunes and Michele Nishioka for their valuable contribution in the experiment.

\section{Correspondence:}

Lydia Masako Ferreira

Disciplina de Cirurgia Plástica-UNIFESP

Rua Napoleão de Barros, $715 / 4^{\circ}$ andar

04023-002 São Paulo - SP Brasil

Tel.: (55 11)5576-4118

Fax: (55 11)5539-0824

lydiamferreira@gmail.com

Received: Apr 21, 2015

Review: June 18, 2015

Accepted: July 242015

Conflict of interest: none

Financial source: CNPq (protocol no 138599/2011-4)

${ }^{1}$ Research performed at Division of Plastic Surgery, Department of Surgery, Universidade Federal de São Paulo (UNIFESP), Brazil. 